\title{
STEADY STATE MODELS OF SERIES FACTS DEVICES FOR POWER FLOW ANALYSIS
}

\author{
Venkata Silpa Borra and Ramya Krishna Venna
}

PG Scholar Department of EEE, Prasad V. Potluri Siddhartha Institute of Technology, Vijayawada, Andhra Pradesh, India.

\begin{abstract}
In this paper, steady state models of series FACTS devices for power flow studies and the task of that modelling in the study of series FACTS devices for control of power flow was discussed. Series FACTS devices considered in this paper are Thyristor Controlled Series Capacitor (TCSC), Thyristor Controlled Phase Shifter (TCPS) and Static Synchronous Series Compensator (SSSC). In order to model these series FACTS devices, a number of power flow study programs were established. The effectiveness of modelling and convergence was tested with IEEE 14 and 30 bus system with and without series FACTS devices. Newton-Raphson technique is used to solve the nonlinear load flow equations. Power flow study programming was accomplished by using MATLAB. Results are reported and studies are presented to demonstrate and compare the efficiency of TCPS, TCSC and SSSC.
\end{abstract}

\section{KEYWORDS}

FACTS; Newton Raphson method, Thyristor Controlled Phase Shifter (TCPS), Static Synchronous Series Compensator (SSSC), Thyristor Controlled Series Capacitor (TCSC)

\section{INTRODUCTION}

The power system performance can be improved by controlling power flow without disturbing the generation scheduling or topological changes. Owing to higher power demand and deregulation of power market, the utilisation of transmission assets is increased. It necessitates the impetus for exploring new ways of power transfer enhancing in existing transmission lines. Modern development in power electronic devices has proven to achieve these objectives by introducing the concept of flexible AC transmission system (FACTS) technology. The concept of FACTS is nothing but incorporation of power electronics devices into the high voltage side of the power network so as make it electronically controllable.

FACTS-devices improve the stability and dynamic behaviour and enhance the transmission capacity. The main objectives are power flow control, voltage control, and reactive power compensation. FACTS-devices forever give quick control actions compared to conventional devices like phase shifting transformers with mechanical on-load tap changers or switched compensation due to their controllable power electronics. FACTS devices for enhancing the power flow through the line are introduced either in shunt or in series in transmission line. Series compensation [1] is the most efficient method of increasing power transfer capability of the line. The series devices considered in this paper are Thyristor Controlled Series Capacitor (TCSC) [27], Static Synchronous Series Compensator (SSSC) [7-9] and Thyristor Controlled Phase Shifter (TCPS) [10-11]. For the purpose of positive sequence load flow solutions, TCSC and TCPS characterized as simple controllable branches, the SSSC can be characterized as a 'solid state' Synchronous Voltage Source (SVS). A study tool with strong convergence characteristics is 
needed to know the effectiveness of these devices. This paper presents the Newton-Raphson (NR) algorithm with series controllable branches for the control of power flow. This algorithm important feature is its capability to reach the solution in quadratic convergent fashion.

There are two types of solutions [12] exist for the modelling of series FACTS devices in the NR method, those are sequential [13] and simultaneous [2] solution methods. The former one is easy to implement in NR algorithm but it yields no quadratic convergence because in this method only node voltage magnitudes and angles are considered as state variables while sub problem is formulated for updating the state variables of the FACTS devices at the end of each iteration. The latter one combines the state variables of controllable devices with the state variables of the network for simultaneous iterative solution. Implementation of this method is not easy but it gives a good convergence characteristics. The state variables of series devices are adjusted automatically so as to gratify a stipulated power flow. In this paper simultaneous method is used for modelling of controllable branches in the NR method. Standard IEEE 14 and 30 bus test system is used for convergence studies and to test the effectiveness of the proposed models.

\section{STEADY STATE MODELS OF SERIES FACTS DEVICE}

Power flow is a function of magnitude of receiving and sending end voltages, impedance of transmission line and the phase angle between the voltages. It is possible to control the real, as well as the reactive power flow in the transmission line by controlling one or a combination of these power flow arguments. A simple model of transmission line is shown in Figure.1.

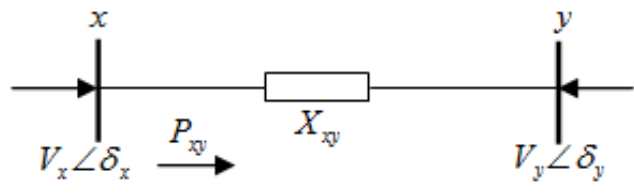

Figure 1.Transmission line representation between buses

The power flow through the transmission line $x-y$ is given by

$$
P_{x y}=\frac{V_{x} V_{y}}{X_{x y}} \sin \left(\delta_{x}-\delta_{y}\right)
$$

Where $P_{x y}=$ Power flow through the transmission line x-y

$X_{x y}=$ Transmission Line Reactance

$V_{x}$ and $\delta_{x}$ are the magnitude and phase angle of bus voltage at node $\mathrm{x}$

$V_{y}$ and $\delta_{y}$ are the magnitude and phase angle of bus voltage at node $\mathrm{y}$

The basic idea behind the FACTS controllers are to enable control of these parameters in realtime and, thus, vary the transmitted power according to system conditions. TCSC controls the reactance of transmission line and TCPS controls the phase angle between the voltages so as to rule the power flow through the transmission line. SSSC is the most versatile member of FACTS family and control line impedance, bus voltage and phase angles. 


\subsection{Steady State Model of TCSC Device}

The basic idea behind the TCSC is to decrease or increase the overall effective series transmission reactance which implies that the amount of power flow through the transmission line can be increased or decreased from the natural power flow. The equivalent circuit of TCSC is shown in Figure.2. The steady state power flow model of TCSC is based on the idea of changeable effective transmission series reactance. The value of which is changed automatically to restrict the branch power at specified value. The reactance value of TCSC is determined effectively by using NR method.

The equivalent reactance of TCSC device $X_{T C S C}$ is given by

$X_{T C S C}=-X_{C}+C_{1}(2(\pi-\alpha)+\sin (2(\pi-\alpha)))-C_{2} \cos ^{2}(\pi-\alpha)(\bar{\omega} \tan (\bar{\omega}(\pi-$ $\alpha))-\tan (\pi-\alpha))$

Where

$$
\begin{gathered}
X_{L C}=\frac{X_{C} X_{L}}{X_{C}-X_{L}} \\
C_{1}=\frac{X_{C}+X_{L C}}{\pi} \\
C_{2}=\frac{4 X_{L C}^{2}}{X_{L} \pi}
\end{gathered}
$$

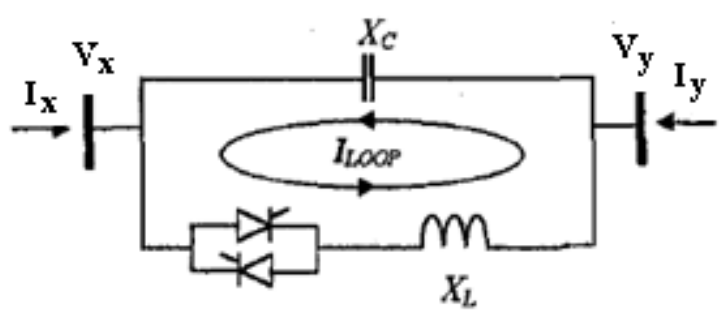

Figure 2.Equivalent circuit of TCSC

The TCSC admittance matrix from the TCSC equivalent circuit shown in Fig. 2 is given by

$$
\left[\begin{array}{l}
I_{x x} \\
I_{y}
\end{array}\right]=\left[\begin{array}{ll}
j B_{x x} & j B_{x y} \\
j B_{y x} & j B_{y y}
\end{array}\right]\left[\begin{array}{l}
V_{x} \\
V_{y}
\end{array}\right]
$$

where

$$
\begin{gathered}
B_{x x}=B_{y y}=B_{T C S C}=-\frac{1}{x_{T C S C}} \\
B_{x y}=B_{y x}=-B_{T C S C}=\frac{1}{x_{T C S C}}
\end{gathered}
$$

The equations for real and reactive power at bus $\mathrm{x}$ and $\mathrm{y}$ are:

$$
\begin{gathered}
P_{x}=-V_{x} V_{y} B_{T C S C} \sin \left(\delta_{x}-\delta_{y}\right) \\
Q_{x}=-V_{x}^{2} B_{T C S C}+V_{x} V_{y} B_{T C S C} \cos \left(\delta_{x}-\delta_{y}\right) \\
P_{y}=-V_{x} V_{y} B_{T C S C} \sin \left(\delta_{y}-\delta_{x}\right) \\
Q_{y}=-V_{y}^{2} B_{T C S C}+V_{x} V_{y} B_{T C S C} \cos \left(\delta_{y}-\delta_{x}\right)
\end{gathered}
$$


The linearised algebraic load flow equations when this controllable device regulates the power flow from node $\mathrm{x}$ to $\mathrm{y}$ is

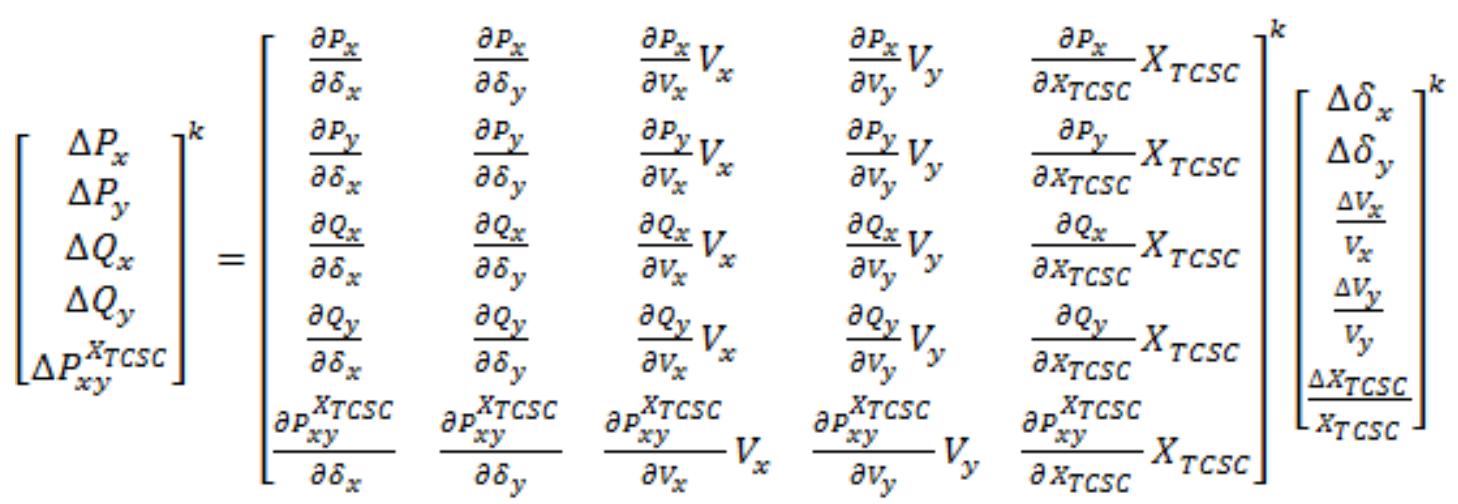

Where $\Delta P_{x y}^{X_{T C S C}}=\Delta P_{x y}^{r e g}-\Delta P_{x y}^{X_{T C S C_{v}} \text { cal }}$, is the real power flow mismatch equation and $\Delta X_{T C S C}=X_{T C S C}^{k}-X_{T C S C}^{(k-1)}$ is the series reactance incremental change. The TCSC controlled parameter $X_{T C S C}$ considered as state variable is updated at the end of each iteration k given by

$$
X_{T C S C}^{k}=X_{T C S C}^{(k-1)}+\left(\frac{\Delta X_{T C S C}}{X_{T C S C}}\right)^{(k)} X_{T C S C}^{(k-1)}
$$

\subsection{Steady State Model of SSSC Device}

SSSC is a switching converter type series compensator, consist of voltage source converter. Active power flow control is the main objective for the addition of SSSC in the line. SSSC generates a quasi-sinusoidal AC output voltage with variable phase angle and magnitude and is in quadrature with the transmission line current. Hence, the line injected voltage emulates a capacitive or an inductive reactance in series with a transmission line, which increases or decreases the total transmission line reactance, resulting in reduce or enhance the power flow in the transmission line. The steady state power flow model of SSSC is based on the idea of changeable voltage magnitude and phase angle. The value of which is changed automatically to restrict the branch power at specified value. The equivalent circuit of SSSC is shown in Figure.3.

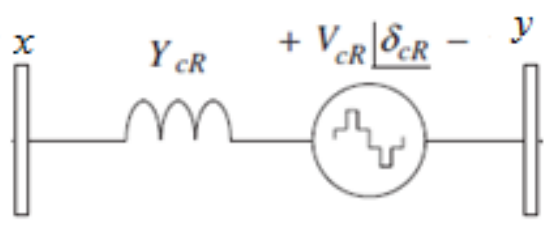

Figure 3.SSSC Equivalent Circuit

The SSSC injected voltage may be characterized by

$$
E_{c R}=V_{c R}\left(\cos \delta_{c R}+j \sin \delta_{c R}\right)
$$

The voltage source indicating the SSSC phase angle $\delta_{c R}$ and magnitude $V_{c R}$ are limited between limits $\left(0 \leq \delta_{c R} \leq 2 \pi\right)$ and $\left(V_{c R_{2} \min } \leq V_{c R} \leq V_{c R_{o} \max }\right)$, respectively. 
Electrical and Electronics Engineering: An International Journal (ELELIJ) Vol 4, No 3, August 2015

In the load flow problem two new state variables $\left(V_{C R}\right.$ and $\left.\delta_{C R}\right)$ are introduced owing to existence of $E_{c R}$. Hence, two new equations are required for the solution of load flow. The admittance equation of equivalent circuit shown in Fig. 3 can be written as:

$$
\left[\begin{array}{l}
I_{x} \\
I_{y}
\end{array}\right]=\left[\begin{array}{ccc}
Y_{c R} & -Y_{c R} & -Y_{c R} \\
-Y_{c R} & Y_{c R} & Y_{c R}
\end{array}\right]\left[\begin{array}{c}
V_{x} \\
V_{y} \\
E_{c R}
\end{array}\right]
$$

The equations for real and reactive power at bus $\mathrm{x}$ written from the Fig. 3 and (11) is given by:

$P_{x}=V_{x}^{2} G_{x x}+V_{x} V_{y}\left[G_{x y} \cos \left(\delta_{x}-\delta_{y}\right)+B_{x y} \sin \left(\delta_{x}-\delta_{y}\right)\right]+V_{x} V_{c R}\left[G_{x y} \cos \left(\delta_{x}-\right.\right.$ $\left.\left.\delta_{c R}\right)+B_{x y} \sin \left(\delta_{x}-\delta_{c R}\right)\right]$

$Q_{x}=-V_{x}^{2} B_{x x}+V_{x x} V_{y}\left[G_{x y} \sin \left(\delta_{x}-\delta_{y}\right)-B_{x y} \cos \left(\delta_{x}-\delta_{y}\right)\right]+V_{x} V_{c R}\left[G_{x y} \sin \left(\delta_{x}-\right.\right.$ $\left.\left.\delta_{c R}\right)-B_{x y} \cos \left(\delta_{x}-\delta_{c R}\right)\right]$

And the equations for SSSC are:

$P_{c R}=V_{c R}^{2} G_{y y}+V_{c R} V_{x}\left[G_{x y} \cos \left(\delta_{c R}-\delta_{x}\right)+B_{x y} \sin \left(\delta_{c R}-\delta_{x}\right)\right]+V_{y} V_{c R}\left[G_{y y} \cos \left(\delta_{c R}-\right.\right.$ $\left.\left.\delta_{y}\right)+B_{y y} \sin \left(\delta_{c R}-\delta_{y}\right)\right]$

$Q_{c R}=$

$-V_{c R}^{2} B_{y y}+V_{x} V_{c R}\left[G_{x y} \sin \left(\delta_{c R}-\delta_{x}\right)-B_{x y} \cos \left(\delta_{c R}-\delta_{x}\right)\right]+V_{y} V_{c R}\left[G_{y y} \sin \left(\delta_{c R}-\right.\right.$ $\left.\left.\delta_{y}\right)-B_{y y} \cos \left(\delta_{c R}-\delta_{y}\right)\right]$

The linearised algebraic load flow equations when this controllable device regulates the power flow from node $\mathrm{x}$ to $\mathrm{y}$ is

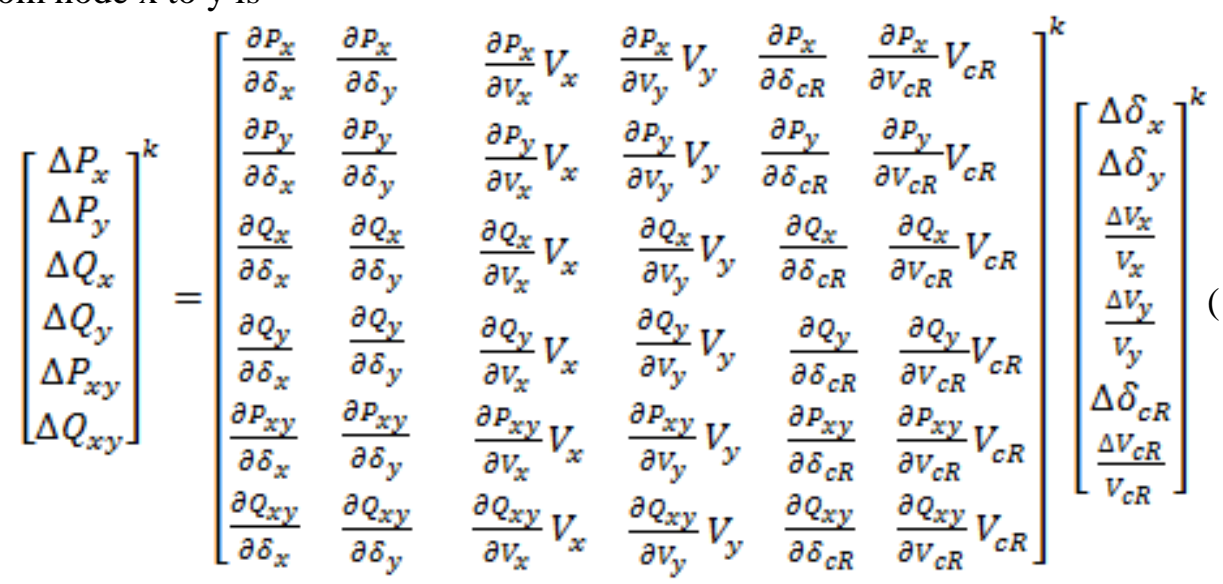




\subsection{TCPS Device Modelling}

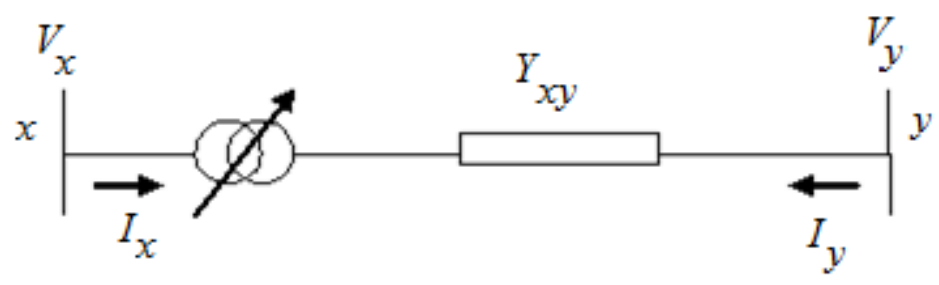

Figure 4.Equivalent circuit of TCPS

Thyristor Controlled Phase shifter with quadrature voltage injection controls the active power via phase adjustment, $\varphi$. It can continuously vary the phase angle between the voltages at the two ends of an insertion transformer without changing the magnitude of the phase-shifted voltage from that of the original line voltage. The steady state power flow model of TCPS is based on the idea of changeable phase angle. The value of which is changed automatically to restrict the branch power at specified value. The equivalent circuit of TCPS is shown in Fig. 4. The admittance equation of equivalent circuit shown in Figure. 4 can be written as:

$$
\left[\begin{array}{l}
I_{x} \\
I_{y}
\end{array}\right]=\left[\begin{array}{cc}
Y & -Y(\cos \varphi+j \sin \varphi) \\
-Y(\cos \varphi-j \sin \varphi) & Y
\end{array}\right]\left[\begin{array}{l}
V_{x} \\
V_{y}
\end{array}\right]
$$

From (17), the nodal power injection equations of TCPS is given by

$$
\begin{aligned}
& P_{x}=V_{x}^{2} G_{x x}+V_{x} V_{y}\left[G_{x y} \cos \left(\delta_{x}-\delta_{y}\right)+B_{x y} \sin \left(\delta_{x}-\delta_{y}\right)\right] \\
& Q_{x}=-V_{x}^{2} G_{x x}+V_{x} V_{y}\left[G_{x y} \sin \left(\delta_{x}-\delta_{y}\right)-B_{x y} \cos \left(\delta_{x}-\delta_{y}\right)\right] \\
& P_{y}=V_{y}^{2} G_{y y}+V_{y} V_{x x}\left[G_{y x} \cos \left(\delta_{y}-\delta_{x}\right)+B_{y x} \sin \left(\delta_{y}-\delta_{x}\right)\right] \\
& Q_{x}=-V_{y}^{2} G_{y y}+V_{y} V_{x}\left[G_{y x} \sin \left(\delta_{y}-\delta_{x}\right)-B_{y x} \cos \left(\delta_{y}-\delta_{x}\right)\right]
\end{aligned}
$$

where

$$
\left.\begin{array}{c}
Y_{x x}=Y_{y y}=Y \\
Y_{x y}=-Y(\cos \varphi+j \sin \varphi) \\
Y_{y x}=-Y(\cos \varphi-j \sin \varphi)
\end{array}\right\}
$$

If (22) is substitute in (18)-(21), then the modified nodal power injection equations are:

$$
\begin{aligned}
& P_{x}=V_{x}^{2} G-V_{x} V_{y}\left[G \cos \left(\delta_{x}-\delta_{y}-\varphi\right)+B \sin \left(\delta_{x}-\delta_{y}-\varphi\right)\right] \\
& Q_{x}=-V_{x}^{2} B-V_{x} V_{y}\left[G \sin \left(\delta_{x}-\delta_{y}-\varphi\right)-B \cos \left(\delta_{x}-\delta_{y}-\varphi\right)\right] \\
& P_{y}=V_{y}^{2} G-V_{y} V_{x}\left[G \cos \left(\delta_{y}-\delta_{x}+\varphi\right)+B \sin \left(\delta_{y}-\delta_{x}+\varphi\right)\right] \\
& Q_{x}=-V_{y}^{2} B-V_{y} V_{x}\left[G \sin \left(\delta_{y}-\delta_{x}+\varphi\right)-B \cos \left(\delta_{y}-\delta_{x}+\varphi\right)\right]
\end{aligned}
$$

The linearised algebraic load flow equations when this controllable device regulates the power flow from node $\mathrm{x}$ to $\mathrm{y}$ is 
Electrical and Electronics Engineering: An International Journal (ELELIJ) Vol 4, No 3, August 2015

$$
\left[\begin{array}{c}
\Delta P_{x} \\
\Delta P_{y} \\
\Delta Q_{x} \\
\Delta Q_{y} \\
\Delta P_{x y}^{\varphi^{p s}}
\end{array}\right]^{k}=\left[\begin{array}{lllll}
\frac{\partial P_{x}}{\partial \delta_{x}} & \frac{\partial P_{x}}{\partial \delta_{y}} & \frac{\partial P_{x}}{\partial V_{x}} V_{x} & \frac{\partial P_{x}}{\partial V_{y}} V_{y} & \frac{\partial P_{x}}{\partial \varphi} \\
\frac{\partial P_{y}}{\partial \delta_{x}} & \frac{\partial P_{y}}{\partial \delta_{y}} & \frac{\partial P_{y}}{\partial V_{x}} V_{x} & \frac{\partial P_{y}}{\partial V_{y}} V_{y} & \frac{\partial P_{y}}{\partial \varphi} \\
\frac{\partial Q_{x}}{\partial \delta_{x}} & \frac{\partial Q_{x}}{\partial \delta_{y}} & \frac{\partial Q_{x}}{\partial V_{x}} V_{x} & \frac{\partial Q_{x}}{\partial V_{y}} V_{y} & \frac{\partial Q_{x}}{\partial \varphi} \\
\frac{\partial Q_{y}}{\partial \delta_{x}} & \frac{\partial Q_{y}}{\partial \delta_{y}} & \frac{\partial Q_{y}}{\partial V_{x}} V_{x} & \frac{\partial Q_{y}}{\partial V_{y}} V_{y} & \frac{\partial Q_{y}}{\partial \varphi} \\
\frac{\partial P_{x y}^{\varphi}}{\partial \delta_{x}} & \frac{\partial p_{x y}^{\varphi}}{\partial \delta_{y}} & \frac{\partial p_{x y}^{\varphi}}{\partial V_{x}} V_{x} & \frac{\partial p_{x y}^{\varphi}}{\partial V_{y}} V_{y} & \frac{\partial p_{x y}^{\varphi}}{\partial \varphi}
\end{array}\right]^{k}\left[\begin{array}{c}
\Delta \delta_{x} \\
\Delta \delta_{y} \\
\frac{\Delta V_{x}}{V_{x}} \\
\frac{\Delta V_{y}}{V_{y}} \\
\Delta \varphi^{p s}
\end{array}\right]
$$

Where $\Delta P_{x y}^{\varphi^{p s}}=P_{x y}^{\varphi, r e g}-P_{x y}^{\varphi^{p s}}$, is the real power flow mismatch equation and $\Delta \varphi^{p s}=\varphi^{(k+1)}-\varphi^{(k)}$, is the phase shifter angle incremental change. The TCPS controlled parameter $\varphi^{p s}$, considered as state variable, is updated at the end of each iteration k given by

$$
\varphi^{K}=\varphi^{(K-1)}+\Delta \varphi_{P S}^{K}
$$

\section{TEST CASE AND SIMULATION}

A software program including the models explained above has been developed and tested expansively on standard IEEE 14 and 30 bus test system. The system essential IEEE 30 bus data is taken from [14] and IEEE 14 bus data is shown in Appendix. Four cases have been studied. First case is conventional Newton Raphson method i.e. excluding FACTS devices and the other cases are modified NR with controllable devices. In cases 2-4, the transmission line is installed with TCPS, TCSC and SSSC respectively.

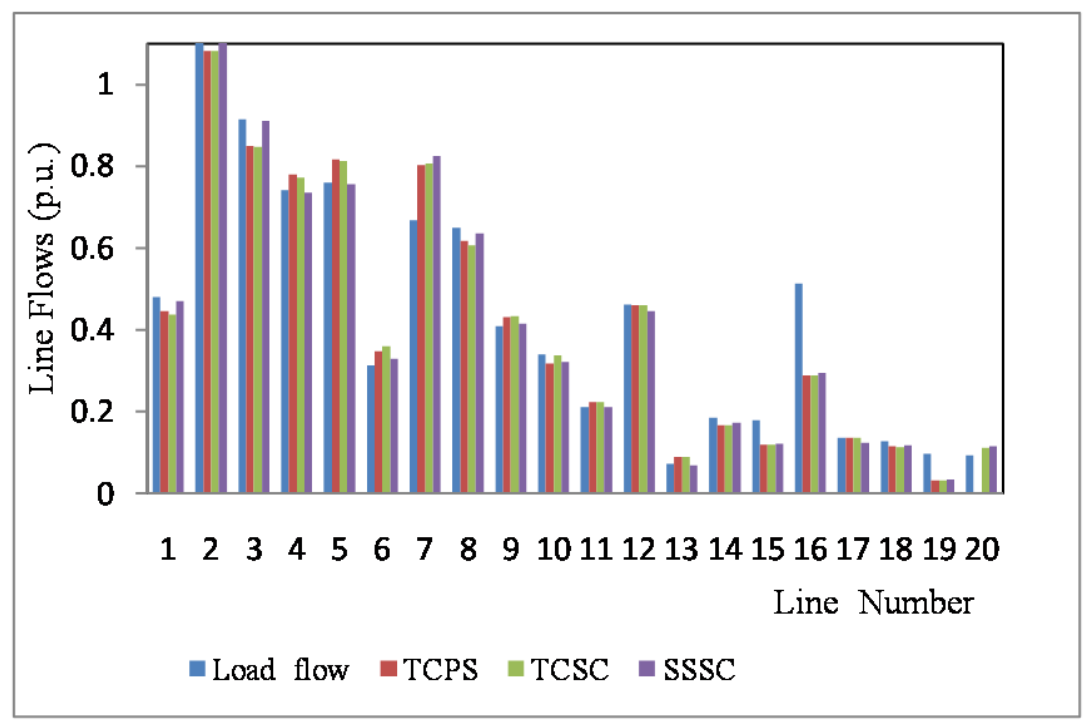

Figure 5. Simulation results of Line flows under 4 cases for IEEE 14 bus system 
Electrical and Electronics Engineering: An International Journal (ELELIJ) Vol 4, No 3, August 2015

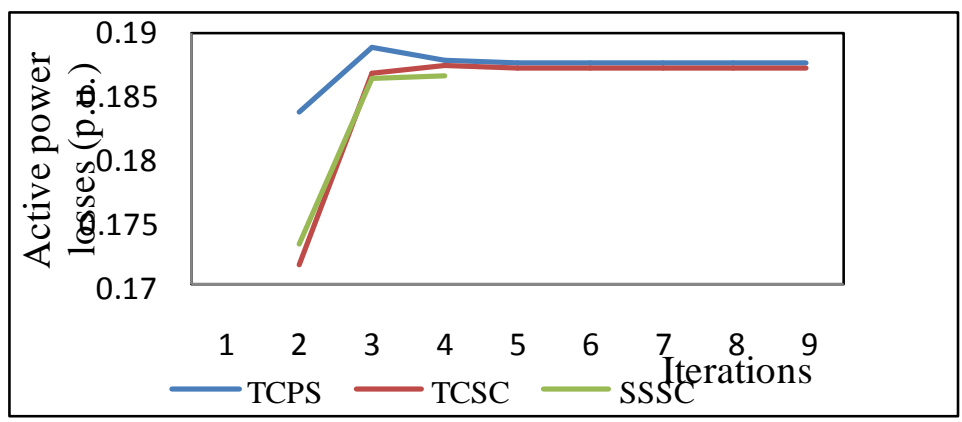

Figure 6.Active power loss during each iteration under case 2, 3 and 4 for IEEE 14 bus system

In the IEEE 14 bus system, transmission line 7 i.e. connecting the nodes 4 and 5 is installed with proposed series controllable device. The power flow in the FACTS controlled line is controlled at a pre-defined value. The specified value is fixed at 0.80 p.u. In the conventional case the active power flowing in the line 12 is $67.29 \mathrm{MW}$. With installing these devices the power flowing in the controlled line increases from 67.29 MW to $80 \mathrm{MW}$. The result of line flows under four cases is shown in Figure.5. The variation of Active power losses under case 2 4 is shown in Figure.6.

The convergence process of FACTS controlled parameter values are shown in Figure 7. Figure 10. The voltage magnitude and phase angles and FACTS controlled parameter values to maintain $80 \mathrm{MW}$ in the controlled line under four cases is shown in Table 1 and Table 2 respectively.

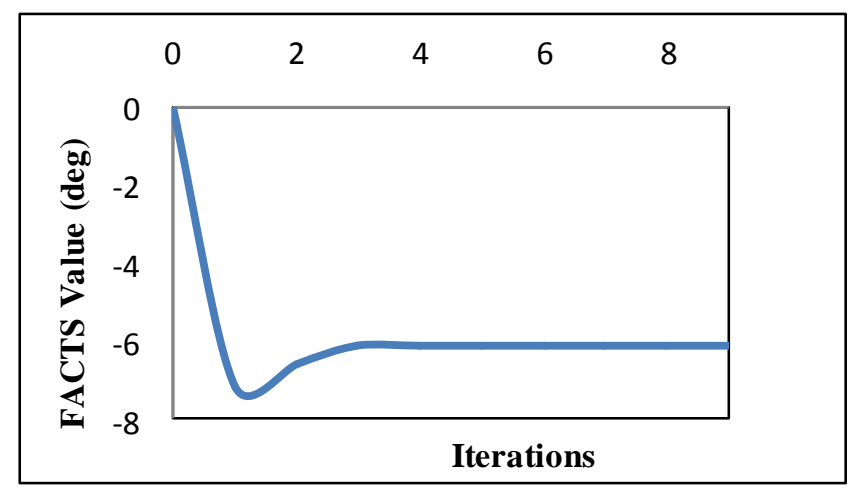

Figure 7. Convergence processes of FACTS parameter values in Case 2 for IEEE 14 bus system

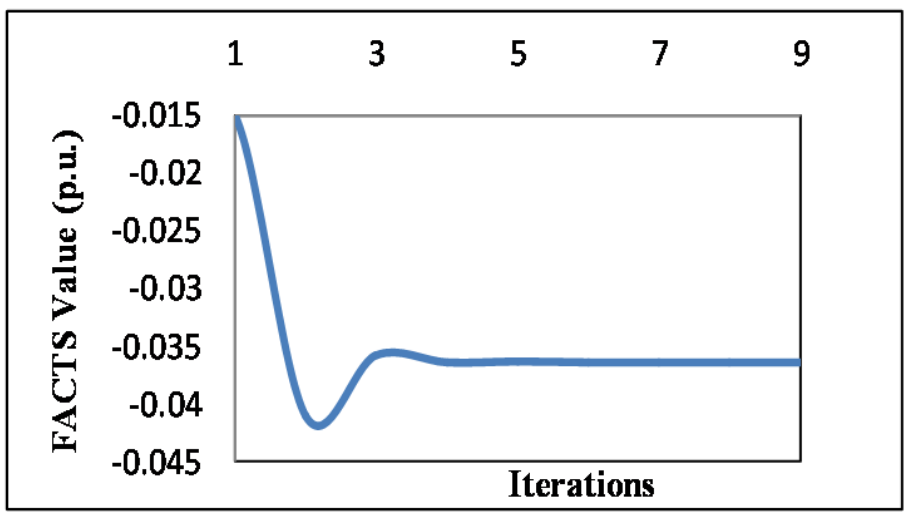

Figure 8. Convergence processes of FACTS parameter values in Case 3 for IEEE 14 bus system 
Electrical and Electronics Engineering: An International Journal (ELELIJ) Vol 4, No 3, August 2015

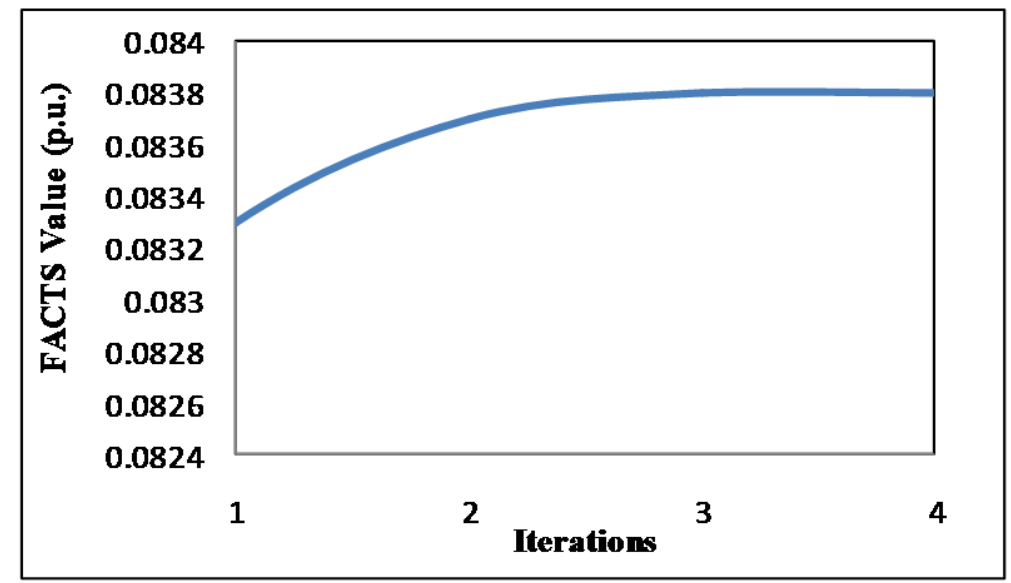

Figure 9.Convergence processes of $V_{c R}$ in Case 4 for IEEE 14 bus system

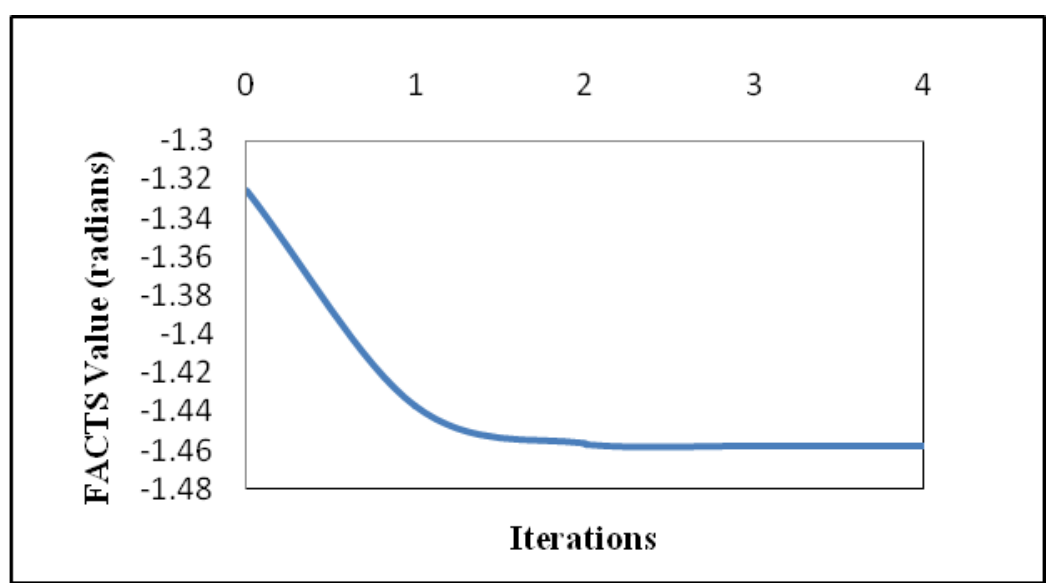

Figure10. Convergence processes of $\delta_{c R}$ in Case 4 for IEEE 14 bus system

Table 1. Voltage magnitudes and phase angle results for IEEE 14 bus system

\begin{tabular}{|c|c|c|c|c|c|c|c|c|}
\hline $\begin{array}{c}\text { Bus no } \\
(\mathbf{x})\end{array}$ & \multicolumn{2}{|c|}{ Case 1 } & \multicolumn{2}{c|}{ Case-2 } & \multicolumn{2}{c|}{ Case-3 } & \multicolumn{2}{c|}{ Case-4 } \\
\cline { 2 - 8 } & $\begin{array}{c}V_{x} \\
\text { in pu }\end{array}$ & $\begin{array}{c}\delta_{x} \\
\text { in deg }\end{array}$ & $\begin{array}{c}V_{x} \\
\text { in pu }\end{array}$ & $\begin{array}{c}\delta_{x} \\
\text { in deg }\end{array}$ & $\begin{array}{c}V_{x} \\
\text { in pu }\end{array}$ & $\begin{array}{c}\delta_{x} \\
\text { in deg }\end{array}$ & $\begin{array}{c}V_{x} \\
\text { in pu }\end{array}$ & $\begin{array}{c}\delta_{x} \\
\text { in deg }\end{array}$ \\
\hline 1 & 1.0600 & 0 & 1.0600 & 0 & 1.0600 & 0 & 1.0600 & 0 \\
2 & 1.0450 & -1.3285 & 1.0450 & -0.0205 & 1.0450 & -1.1667 & 1.0450 & -1.2880 \\
3 & 1.0100 & -13.3094 & 1.0100 & -0.2231 & 1.0100 & -12.7792 & 1.0100 & -13.2261 \\
4 & 0.9948 & -10.0428 & 0.9963 & -0.1605 & 0.9951 & -9.1704 & 0.9962 & -9.9539 \\
5 & 1.0018 & -8.3854 & 0.9980 & -0.1530 & 1.0052 & -8.8161 & 1.0029 & -8.3353 \\
6 & 1.0700 & -16.6129 & 1.0700 & -0.2871 & 1.0700 & -16.4386 & 1.0700 & -16.3516 \\
7 & 1.0319 & -14.4486 & 1.0358 & -0.2409 & 1.0353 & -13.7811 & 1.0354 & -14.3442 \\
8 & 1.0900 & -14.4486 & 1.0900 & -0.2409 & 1.0900 & -13.7811 & 1.0900 & -14.3442 \\
9 & 1.0057 & -16.7912 & 1.0136 & -0.2833 & 1.0131 & -16.2151 & 1.0126 & -16.6657 \\
10 & 1.0062 & -17.1668 & 1.0129 & -0.2911 & 1.0125 & -16.6625 & 1.0120 & -17.0160 \\
11 & 1.0327 & -17.0487 & 1.0362 & -0.2919 & 1.0360 & -16.7129 & 1.0356 & -16.8457 \\
12 & 1.0252 & -17.5163 & 1.0461 & -0.3072 & 1.0461 & -17.5921 & 1.0461 & -17.5410 \\
13 & 1.0000 & -16.7641 & 1.0368 & -0.3072 & 1.0368 & -17.5892 & 1.0366 & -17.5752 \\
14 & 0.9755 & -18.3417 & 0.9975 & -0.3198 & 0.9972 & -18.3105 & 0.9968 & -18.5574 \\
& & & & & & & & \\
\hline
\end{tabular}


Electrical and Electronics Engineering: An International Journal (ELELIJ) Vol 4, No 3, August 2015

Table 2. FACTS parameter value results for IEEE 14 bus system

\begin{tabular}{|c|c|c|c|c|}
\hline $\begin{array}{l}\text { FACTS } \\
\text { parameters }\end{array}$ & case-1 & case-2 & case-3 & case-4 \\
\hline$\varphi^{p s}(\mathrm{deg})$ & ---- & -6.1451 & ---- & ---- \\
\hline $\mathrm{X}$ & ---- & ---- & -0.0364 & ---- \\
\hline$V_{c R}(\mathrm{p} . \mathrm{u})$ & ---- & ---- & ---- & 0.0838 \\
\hline$\delta_{c R}(\mathrm{deg})$ & ---- & ---- & ---- & -83.4815 \\
\hline
\end{tabular}

In the IEEE 30 bus system, transmission line 7 i.e. connecting the nodes 4 and 6 is installed with proposed series controllable device. In the conventional case the active power flowing in the line 7 is $50.93 \mathrm{MW}$. The FACTS devices are considered for controlling active power at specified value. The specified value is fixed at $70 \mathrm{MW}$. With installing these devices the power flowing in the controlled line increases from 50.93 MW to 70 MW. The result of line flows under four cases is shown in Figure 11. The variation of Active power losses under case 2 4 is shown in Figure 12.

The convergence process of FACTS controlled parameter values are shown in Figure 13 Figure 16. The voltage magnitude and phase angles and FACTS controlled parameter values to maintain $70 \mathrm{MW}$ in the controlled line under four cases is shown in Table 3 and Table 4 respectively.

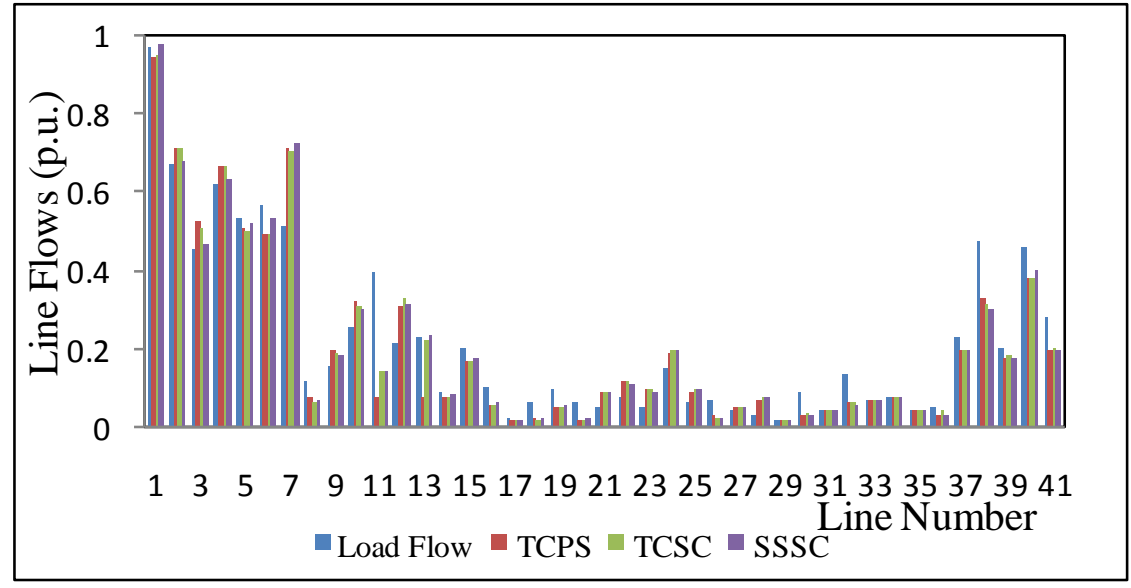

Figure 11. simulation results of Line flows under 4 cases for IEEE 30 bus system

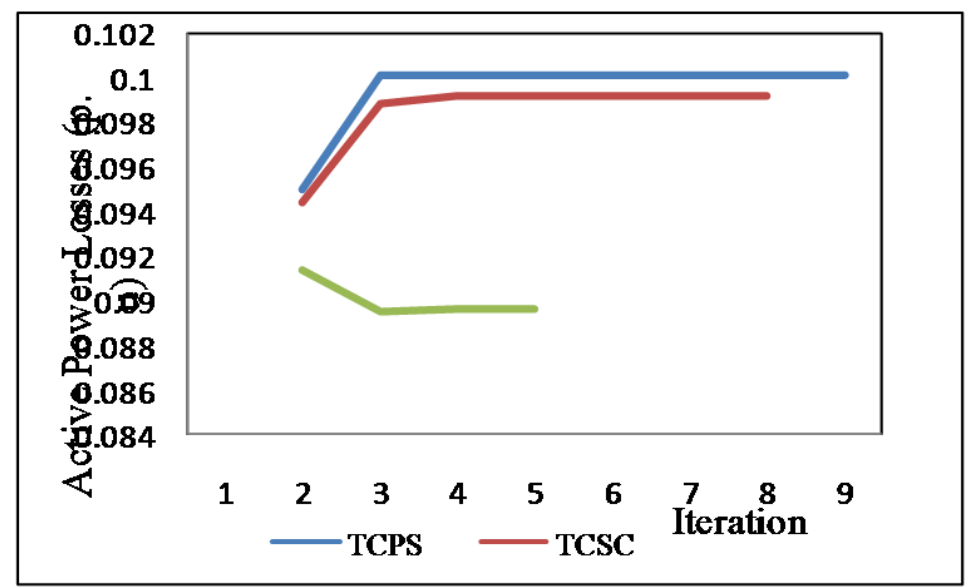

Figure 12. Active power loss during each iteration under case 2, 3 and 4 for IEEE 30 bus system 
Electrical and Electronics Engineering: An International Journal (ELELIJ) Vol 4, No 3, August 2015

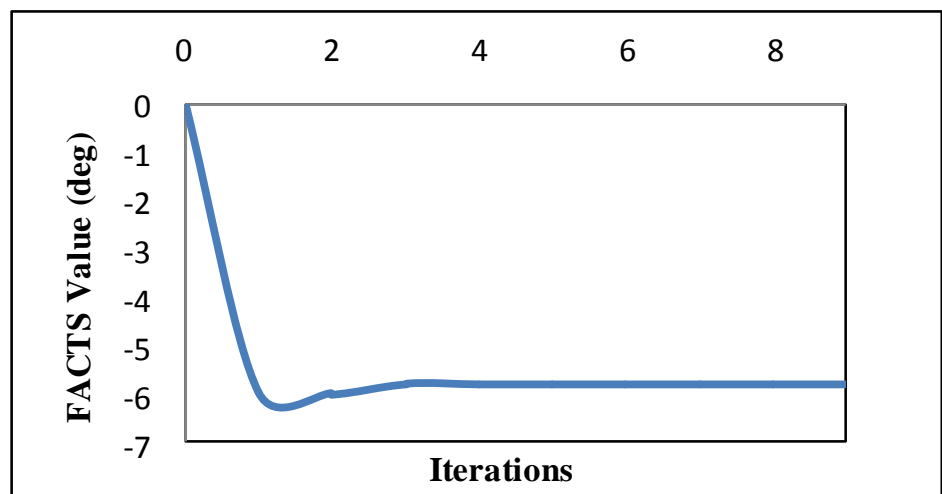

Figure 13.Convergence processes of FACTS parameter values in Case 2 for IEEE 30 bus system

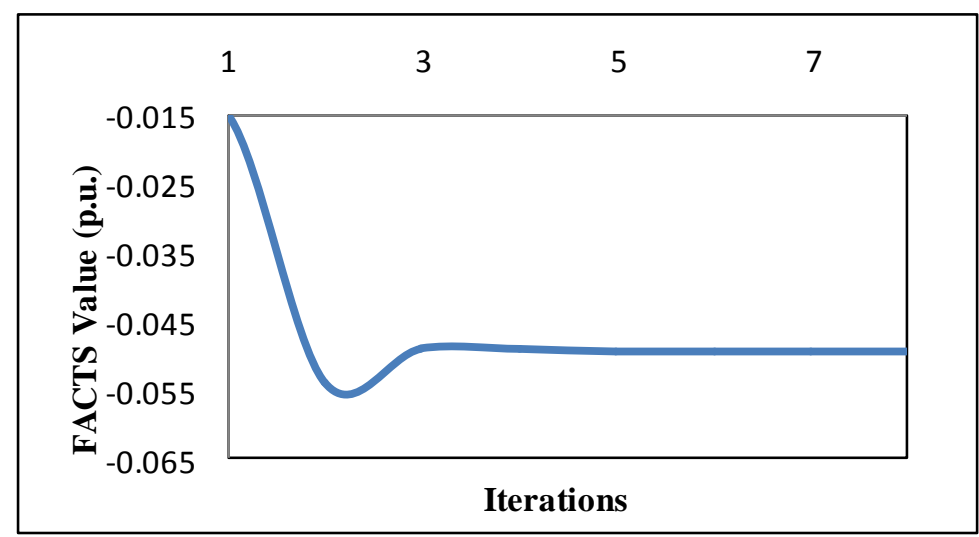

Figure 14.Convergence processes of FACTS parameter values in Case 3 for IEEE 30 bus system

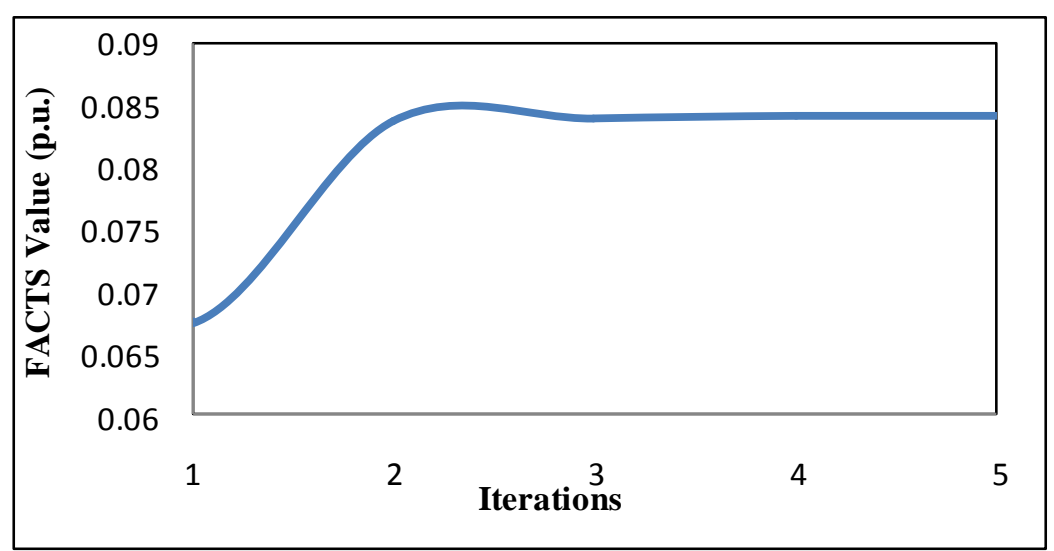

Figure15.Convergence processes of $V_{c R}$ in Case 4 for IEEE 30 bus system 
Electrical and Electronics Engineering: An International Journal (ELELIJ) Vol 4, No 3, August 2015

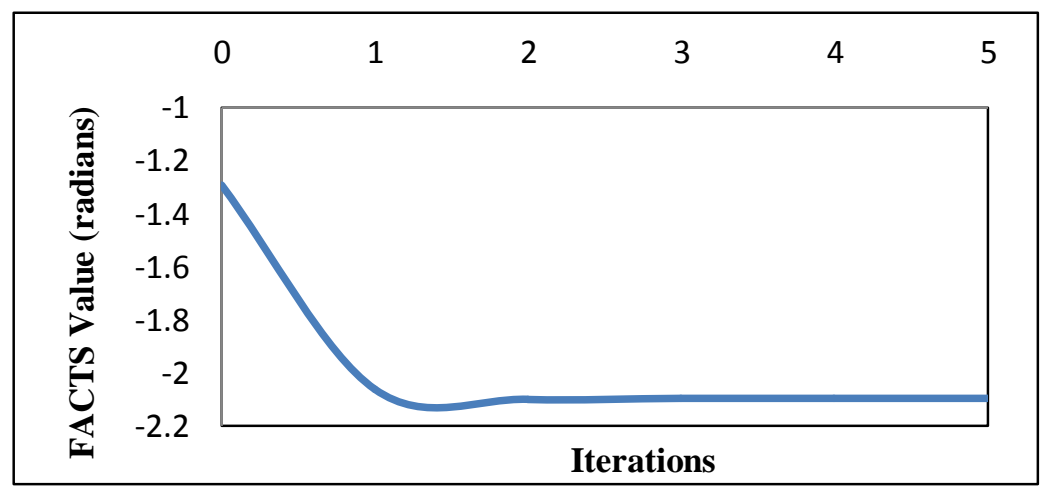

Figure 16.Convergence processes of $\delta_{c R}$ in Case 4 for IEEE 30 bus system

Table 3.Voltage magnitudes and phase angle results for IEEE 30 bus system

\begin{tabular}{|c|c|c|c|c|c|c|c|c|}
\hline \multirow{2}{*}{$\begin{array}{c}\text { Bus no } \\
(\mathbf{x})\end{array}$} & \multicolumn{2}{|c|}{ Case-I } & \multicolumn{2}{|c|}{ Case-II } & \multicolumn{2}{|c|}{ Case-III } & \multicolumn{2}{|c|}{ Case-IV } \\
\hline & $\begin{array}{c}V_{x} \\
\text { in pu }\end{array}$ & $\begin{array}{c}\delta_{x} \\
\text { in deg }\end{array}$ & $\begin{array}{c}V_{x} \\
\text { in pu }\end{array}$ & $\begin{array}{c}\delta_{x} \\
\text { in deg }\end{array}$ & $\begin{array}{c}V_{x} \\
\text { in pu }\end{array}$ & $\begin{array}{c}\delta_{x} \\
\text { in deg }\end{array}$ & $\begin{array}{c}V_{x} \\
\text { in pu }\end{array}$ & $\begin{array}{c}\delta_{x} \\
\text { in deg }\end{array}$ \\
\hline 1 & 1.0600 & 0 & 1.0500 & 0 & 1.0500 & 0 & 1.0500 & 0 \\
\hline 2 & 1.0450 & -2.9041 & 1.0450 & -2.9706 & 1.0450 & -2.9651 & 1.0450 & -3.0469 \\
\hline 3 & 1.0190 & -5.5666 & 1.0109 & -6.1075 & 1.0259 & -6.2506 & 1.0172 & -5.8513 \\
\hline 4 & 1.0086 & -6.8302 & 1.0014 & -7.5104 & 1.0200 & -7.6762 & 1. 0092 & -7.1868 \\
\hline 5 & 1.0100 & -8.4255 & 1.0100 & -8.0787 & 1.0100 & -8.0895 & 1.0100 & -8.3876 \\
\hline 6 & 1.0000 & -7.9819 & 1.0087 & -7.3768 & 1.0107 & -7.4503 & 1.0138 & -8.0523 \\
\hline 7 & 0.9959 & -8.6953 & 1.0011 & -8.1970 & 1.0023 & -8.2451 & 1.0041 & -8.7236 \\
\hline 8 & 1.0100 & -8.2668 & 1.0100 & -8.1600 & 1.0100 & -8.1973 & 1.0100 & -8.7440 \\
\hline 9 & 1.0350 & -13.1470 & 1.0358 & -10.7890 & 1.0212 & -11.0683 & 1.0219 & -11.5017 \\
\hline 10 & 1.0200 & -14.0914 & 1.0322 & -12.5914 & 1.0131 & -12.9762 & 1.0129 & -13.3268 \\
\hline 11 & 1.0820 & -16.3399 & 1.0500 & -10.7890 & 1.0500 & -11.0683 & 1.0500 & -11.5017 \\
\hline 12 & 1.0413 & -13.1037 & 1.0397 & -12.5258 & 1.0198 & -12.9827 & 1.0175 & -12.9149 \\
\hline 13 & 1.0710 & -13.1037 & 1.0500 & -12.5258 & 1.0500 & -12.9827 & 1.0500 & -12.9149 \\
\hline 14 & 1.0255 & -14.0465 & 1.0251 & -13.3509 & 1.0048 & -13.8302 & 1.0029 & -13.8149 \\
\hline 15 & 1.0201 & -14.1497 & 1.0216 & -13.3607 & 1.0012 & -13.8275 & 0.9994 & -13.8702 \\
\hline 16 & 1.0242 & -13.7747 & 1.0293 & -12.8303 & 1.0097 & -13.2690 & 1.0080 & -13.3858 \\
\hline 17 & 1.0163 & -14.2248 & 1.0260 & -12.8847 & 1.0067 & -13.2941 & 1.0061 & -13.5705 \\
\hline 18 & 1.0022 & -14.8485 & 1.0130 & -13.8049 & 0.9929 & -14.2717 & 0.9915 & -14.4248 \\
\hline 19 & 0.9949 & -15.0666 & 1.0111 & -13.8708 & 0.9911 & -14.3294 & 0.9902 & -14.5477 \\
\hline 20 & 1.0117 & -14.8852 & 1.0156 & -13.6095 & 0.9958 & -14.0517 & 0.9950 & -14.3038 \\
\hline 21 & 1.0107 & -14.5083 & 1.0198 & -13.0597 & 1.0000 & -13.4623 & 0.9997 & -13.8037 \\
\hline 22 & 1.0123 & -14.4799 & 1.0204 & -13.0498 & 1.0004 & -13.4517 & 1.0002 & -13.7901 \\
\hline 23 & 1.0143 & -14.5675 & 1.0126 & -13.5714 & 0.9914 & -14.0178 & 0.9902 & -14.1692 \\
\hline 24 & 1.0150 & -14.7662 & 1.0091 & -13.4932 & 0.9870 & -13.8969 & 0.9867 & -14.1938 \\
\hline 25 & 1.0446 & -14.1773 & 1.0094 & -12.8697 & 0.9835 & -13.1891 & 0.9839 & -13.5999 \\
\hline 26 & 1.0274 & -14.5748 & 0.9916 & -13.2959 & 0.9652 & -13.6385 & 0.9656 & -14.0490 \\
\hline 27 & 1.0712 & -13.5479 & 1.0182 & -12.2177 & 0.9902 & -12.4729 & 0.9910 & -12.9539 \\
\hline 28 & 1.0040 & -8.7429 & 1.0050 & -8.0387 & 1.0070 & -8.1028 & 1.0093 & -8.6788 \\
\hline 29 & 1.0524 & -14.6677 & 0.9983 & -13.4595 & 0.9696 & -13.7877 & 0.9704 & -14.2665 \\
\hline 30 & 1.0415 & -15.4691 & 0.9867 & -14.3512 & 0.9577 & -14.7336 & 0.9586 & -15.2107 \\
\hline
\end{tabular}


Table 4.FACTS parameter value results for IEEE 30 bus system

\begin{tabular}{|c|c|c|c|c|}
\hline$\varphi^{p s}(\mathrm{deg})$ & ---- & -5.8050 & ---- & ---- \\
\hline $\mathrm{X}$ & ---- & ---- & -0.0493 & ---- \\
\hline$V_{c R}(\mathrm{p} . \mathrm{u})$ & ---- & ---- & --- & 0.0841 \\
\hline$\delta_{c R}(\mathrm{deg})$ & ---- & ---- & ---- & -120.1511 \\
\hline
\end{tabular}

From these figures we can observe several points. From Figure 5 and Figure 11, it can observe that the SSSC controlled branch carries more power compared to TCSC and TCPS. From Figure 6 and Figure.12, it can observe that the SSSC has less Active power loss compared to TCSC and TCPS. And also observe that SSSC has better convergence characteristics compared to TCSC and TCPS. From Figure.7 10 and Figure. 13 16, it can observe that the controlled parameter values converge smoothly with some slight oscillations in the former iterations. The number of iterations required for convergence is less than 10 times so it shows that the proposed approach is effective.

\section{CONCLuSion}

An effective and reliable method for controlling of power flow in an electrical network has been presented in this paper. The regulation of power flow across selected branches is done by incorporating the suitable model of proposed series FACTS devices in NR load flow algorithm, which is capable for solving large power networks. Key aspects of modelling implementation of proposed series FACTS devices within the NR power flow algorithm have been presented. A standard IEEE 14 and 30 bus system is used for testing the effectiveness of the proposed models of the series FACTS devices. The results illustrates that SSSC minimizes more active power loss and carries high power compared to both TCSC and TCPS. And also SSSC has better convergent characteristics compared to TCSC and TCPS.

\section{REFERENCES}

[1] N.G.Hingorani \& L. Gyugyi, (2000) "Understanding FACTS: Concepts And Technology Of Flexible AC Transmission Systems, ”New York: IEEE Press.

[2] C.R.Feurte Esquivel \& E. Acha, (1997) "A Newton-Type Algorithm For The Control Of Power Flow In Electrical Power Networks,” IEEE Transactions On Powersystem, Vol. 12, Pp1474- 1481.

[3] D. J. Gotham \& G. T. Heydt, (1998) "Power Flow Control And Power Flow Studies For System With FACTS Devices," IEEE Transactions Power System, Vol. 13, Pp60-66.

[4] Povh.D, (2000) "Modeling Of FACTS In Power System Studies," Proceedings IEEE Power Engineerig Winter Meeting, Pp1435-1439.

[5] C.R.Fuerte-Esquivel,E.Acha \& H. Ambriz-Pbrez,(2000) “A Thyristor Controlled Series Compensator Model For The Power Flow Solution Of Practical Power Networks," IEEE Transactions Powersystem, Vol. 15, No. 1, Pp58-64.

[6] Ramakrishna N, Choppa A.K, \& Sreekanth. B, (2013) "A Real Time Lab Scaled Thyristor Controlled Series Compensation (TCSC) Model For Voltage Regulation Studies," International Conference On Energy Efficient Technologies For Sustainability (ICEETS), Pp1315- 1319.

[7] Metin Dogan, Salih Tosun, Ali Ozturk \& M. Kenan Dosoglu, (2011) "Investigation Of TCSC And SSSC Controller Effects On The Power System,” Electrical And Electronics Engineering (ELECO), 7th International Conference, Ppi-127 - I-131.

[8] Alireza Seifi, Sasan Gholami \& Amin Shabanpour, (2010) "Power Flow Study And Comparison Of FACTS: Series (SSSC), Shunt (STATCOM), And Shunt-Series (UPFC)" The Pacific Journal Of Science And Technology, Vol. 11, No. 1, Pp129-137.

[9] Zhang,X.P, (2003) “Advanced Modeling Of Multicontrol Functional Static Synchronous Series Compensator (SSSC) In Newton-Raphson Power Flow," IEEE Transactions On Power System, Vol. 18, No. 4, Pp1410-1416.

[10] Enrique Ache, Claudio R. Fuerte-Esquivel \& Hugo Ambriz-Perez,(2004)"FACTS:Modeling And Simulation In Power Networks", John Wiley \& Sons LTD. 
[11] M. R. Iravani \& D. Maratukulam, (1994) "Review Of Semiconductorcontrolled (Static) Phase Shifters For Power Systems Applications”, IEEE Transactions On Power Systems, Vol. 9, No. 4, Pp1833-1839.

[12] U. P. Mhaskar, A. B. Mote \& A. S M. Kulkarni, (2003) “A New Formulation For Load Flow Solution Of Power Systems With Eries FACTS Devices”, IEEE Transactions On Power System, Vol. 18, No. 4, Pp1307-1315.

[13] M.Noroozian \& G. Anderson, (1993) "Power Flow Control By Use Of Controllable Series Components", IEEE Transactions On Power Delivery, Vol. 8, Pp1420-1429.

[14] Alsac \& B. Stott, (May/June 1974) “Optimal Load Flow With Steady State Security" IEEE Transactions On Power Apparatus And Systems,Vol. PAS-93, Pp745-751.

\section{AUTHORS}

B.Venkata Silpa received her M.Tech (Power System Automation and Control) in the Department of Electrical \& Electroncics Engineering, from Prasad.V.Potluri Siddhartha Institute of Technology, Vijayawada, Andhra Pradesh, India. She obtained B.Tech degree in Electrical and Electronics Engineering from J.N.T.U Kakinada in the year 2010.

V. Ramya Krishna received her M.Tech (Power System Automation and Control) in the Department of Electrical \& Electroncics Engineering, from Prasad. V .Potluri Siddhartha Institute of Technology, Vijayawada, Andhra Pradesh, India. She obtained B.Tech degree in Electrical and Electronics Engineering from J.N.T.U Kakinada in the year 2010.
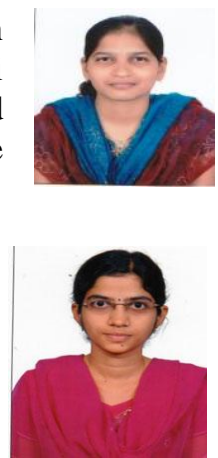